\title{
PENDETEKSI CITRA MASKER WAJAH MENGGUNAKAN CNN DAN TRANSFER LEARNING
}

\author{
Mohammad Farid Naufal ${ }^{* 1}$, Selvia Ferdiana Kusuma ${ }^{2}$ \\ ${ }^{1}$ Universitas Surabaya, Surabaya, ${ }^{2}$ PSDKU Politeknik Negeri Malang, Kediri \\ Email: ${ }^{1 *}$ faridnaufal@staff.ubaya.ac.id, ${ }^{2}$ selvia.ferdiana@polinema.ac.id, \\ *Penulis Korespondensi
}

(Naskah masuk: 26Juni 2021, diterima untuk diterbitkan: 17 November 2021)

\begin{abstract}
Abstrak
Pada tahun 2021 pandemi Covid-19 masih menjadi masalah di dunia. Protokol kesehatan diperlukan untuk mencegah penyebaran Covid-19. Penggunaan masker wajah adalah salah satu protokol kesehatan yang umum digunakan. Pengecekan secara manual untuk mendeteksi wajah yang tidak menggunakan masker adalah pekerjaan yang lama dan melelahkan. Computer vision merupakan salah satu cabang ilmu komputer yang dapat digunakan untuk klasifikasi citra. Convolutional Neural Network (CNN) merupakan algoritma deep learning yang memiliki performa bagus dalam klasifikasi citra. Transfer learning merupakan metode terkini untuk mempercepat waktu training pada CNN dan untuk mendapatkan performa klasifikasi yang lebih baik. Penelitian ini melakukan klasifikasi citra wajah untuk membedakan orang menggunakan masker atau tidak dengan menggunakan CNN dan Transfer Learning. Arsitektur CNN yang digunakan dalam penelitian ini adalah MobileNetV2, VGG16, DenseNet201, dan Xception. Berdasarkan hasil uji coba menggunakan 5-cross validation, Xception memiliki akurasi terbaik yaitu 0.988 dengan waktu total komputasi training dan testing sebesar 18274 detik. MobileNetV2 memiliki waktu total komputasi tercepat yaitu 4081 detik dengan akurasi sebesar 0.981 .
\end{abstract}

Kata kunci: face mask classification, CNN, Transfer Learning, MobileNetV2, VGG16, DenseNet201, Xception

\section{FACE MASK IMAGE DETECTION USING CNN AND TRANSFER LEARNING}

\begin{abstract}
In 2021 the Covid-19 pandemic is still a problem in the world. Therefore, health protocols are needed to prevent the spread of Covid-19. The use of face masks is one of the commonly used health protocols. However, manually checking to detect faces that are not wearing masks is a long and tiring job. Computer vision is a branch of computer science that can be used for image classification. Convolutional Neural Network (CNN) is a deep learning algorithm that has good performance in image classification. Transfer learning is the latest method to speed up CNN training and get better classification performance. This study performs facial image classification to distinguish people using masks or not by using CNN and Transfer Learning. The CNN architecture used in this research is MobileNetV2, VGG16, DenseNet201, and Xception. Based on the results of trials using 5-cross validation, Xception has the best accuracy of 0.988 with a total computation time of training and testing of 18274 seconds. MobileNetV2 has the fastest total computing time of 4081 seconds with an accuracy of 0.981.
\end{abstract}

Keywords: face mask classification, CNN, Transfer Learning, MobileNetV2, VGG16, DenseNet201, Xception

\section{PENDAHULUAN}

Pandemi Covid-19 menjadi masalah besar di dunia pada tahun 2020. Hingga pertengahan tahun 2021, belum bisa diprediksi kapan pandemi Covid-19 akan hilang. Ada banyak perusahaan farmasi yang membuat vaksin Covid-19. Namun, efektivitas vaksin belum teruji $100 \%$ efektif untuk mencegah penyebaran Covid-19. Penerapan protokol kesehatan masih menjadi cara yang paling efektif untuk mencegah penyebaran Covid-19, seperti penggunaan masker wajah. Penggunaan masker wajah sudah menjadi tren di masa pandemi ini. Penggunaan masker wajah juga menjadi kewajiban saat berada di tempat umum. Namun, masih ada masyarakat yang tidak mematuhi protokol kesehatan dengan tidak menggunakan masker wajah. Sistem yang dapat mendeteksi wajah tidak bermasker adalah cara yang efektif untuk meningkatkan penerapan protocol Kesehatan.

(Grassi and Faundez-Zanuy, 2007) menggunakan Discrete Cosine Transform (DCT) 
untuk ekstraksi fitur dengan Multilayer Perceptron (MLP) dan RBF Neural Network sebagai classifier. Penelitian ini menghasilkan akurasi sebesar $84 \%$. (Ge et al., 2017) mengusulkan Locally Linear Embedding (LLE) - CNN untuk deteksi masker wajah. Penelitian ini menggabungkan dua CNN pra-terlatih untuk mengekstraksi daerah wajah kemudian LLE akan digunakan sebagai deskriptor. (Jagadeeswari and Theja, 2020) membandingkan MobileNetV2, RESNET50, VGG16 masing-masing dengan Pengoptimal Adam, ADAGRAD, dan SGD. Pengoptimal Adam dan MobileNetV2 memiliki akurasi terbaik yaitu 93\%. (Han et al., 2020) menyajikan deteksi objek yang berfokus pada deteksi masker wajah secara real time di supermarket menggunakan single-shot detector (SSD) dan menghasilkan akurasi 93\%. (Vinitha and Velantina, 2020) menggunakan CNN dengan arsitektur MobileNetV2, dan library OpenCV, tensorflow, keras, dan Pytorch untuk mendeteksi apakah orang memakai masker wajah atau tidak. (Nagrath et al., 2021) menggunakan SSDMNV2 (Single Shot Multibox Detector sebagai pendeteksi wajah dan MobileNetV2) untuk melakukan deteksi masker wajah secara real-time. Penelitian ini menghasilkan akurasi 92.64\%. (Jignesh Chowdary et al., 2020) menggunakan arsitektur InceptionV3 dan transfer learning untuk mendeteksi masker wajah pada Simulated Masked Face Dataset (SFMD). Akurasi yang dihasilkan pada penelitian ini adalah $100 \%$. Namun penelitian ini diterapkan pada dataset simulasi wajah dengan menambahkan masker secara tidak nyata. (Budiman, 2021) menggunakan arsitektur MobileNetV2 untuk mendeteksi masker wajah. Akurasi yang dihasilkan adalah $84.35 \%$. (Et al., 2021) melakukan perbandingan algoritma VGG16, InceptionV3, ResNet50V2, MobileNetV2, dan Xceptioon untuk pendeteksian masker wajah. Namun analisis yang dilakukan tidak membahas tentang waktu komputasi dari tiap model deep learning. (Siegfried, 2020) melakukan perbandingan arsitektur MobileNetV2, ResNet50V2, dan Xception. Namun tidak ada analisis terkait waktu komputasi yang diperlukan tiap arsitektur.

Dari beberapa penelitian yang telah dilakukan, masih belum terdapat penelitian yang mencoba untuk melakukan pendeteksian citra masker wajah menggunakan beberapa arsitektur CNN dan dilengkapi dengan transfer learning. Selain itu, masih belum ada penelitian yang mencoba untuk melakukan analisis dan perbandingan terhadap performa waktu komputasi dari beberapa arsitektur CNN. Hal ini berguna bagi peneliti untuk memilih arsitektur yang tepat sesuai dengan kebutuhan pendeteksian citra masker wajah.

Penelitian ini bertujuan untuk melakukan pendeteksian citra wajah menggunakan beberapa arsitektur CNN populer yaitu MobileNetV2, VGG16, DenseNet201, dan Exception yang dikombinasikan dengan transfer learning untuk mendeteksi wajah tidak bermasker. Penelitian ini juga memberikan analisis terhadap performa tiap arsitektur sehingga memberikan informasi yang berguna bagi peneliti untuk memilih arsitektur yang tepat.

\section{METODE PENELITIAN}

Metodologi penelitian pada penelitian ini terdiri dari pengumpulan dataset, dataset augmentation, konfigurasi hyperparameter, training, testing, dan perhitungan performa model klasifikasi. Alur metodologi penelitian dapat dilihat pada Gambar 1 .

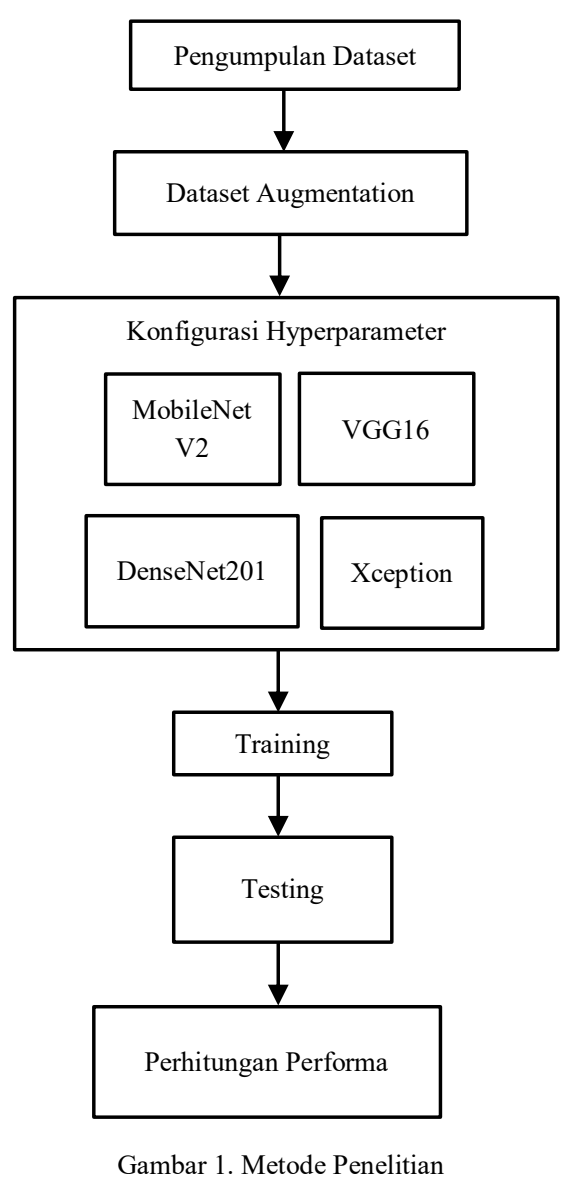

\subsection{Pengumpulan Dataset}

Dataset yang digunakan dalam penelitian ini adalah citra masker wajah yang diperoleh dari Kaggle (Larxel, 2020). Dataset ini adalah dataset publik yang terdiri dari wajah dengan dan tanpa masker. Gambar 2 menunjukkan contoh wajah dengan dan tanpa masker. Jumlah citra dengan masker wajah adalah 3725 dan tanpa masker adalah 3828. Karena dataset citra masker wajah memiliki ukuran citra yang berbeda, maka ukuran citra diubah menjadi 64x64 pixel.

Citra wajah bermasker dan tidak dapat dilihat dari permukaan dengan warna yang sama menutupi bagian hidung dan mulut wajah. Dataset yang digunakan dalam penelitian ini tanpa melakukan pendeteksian objek wajah ataupun segmentasi. Data 
citra yang sudah diubah ukuran menjadi 64x64 pixel dimasukkan dalam proses training model di tiap arsitektur CNN yang dikombinasikan dengan trasnfer learning
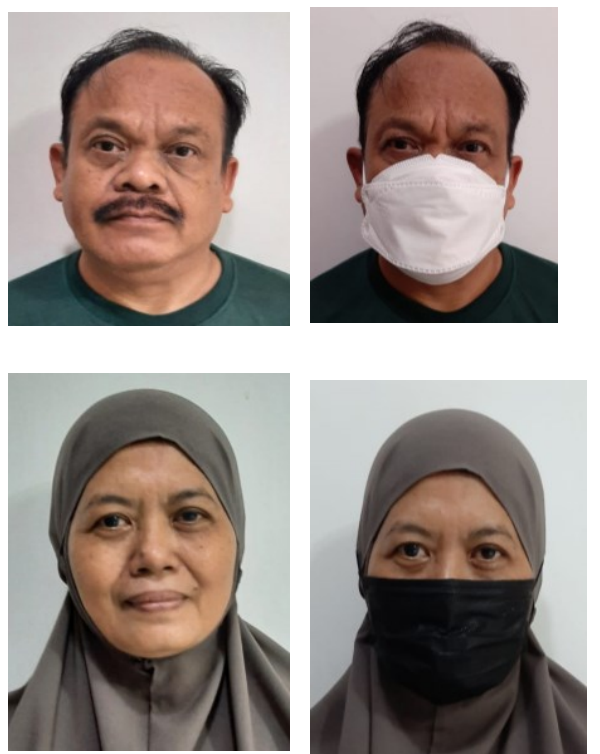

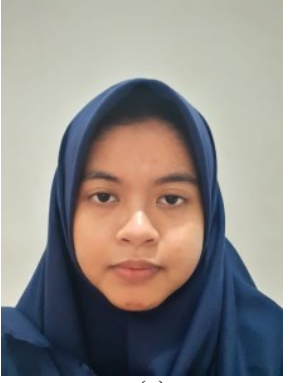

(a)

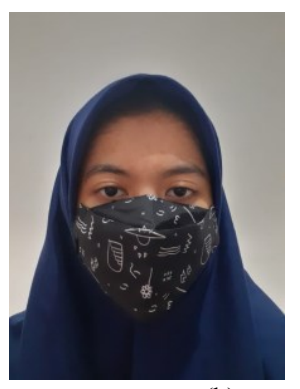

(b)

Gambar 2. Contoh dataset masker wajah

\subsection{Data Augmentation}

Data Augmentation memperkaya data pelatihan untuk menghindari munculnya overfitting. Augmentasi data menggunakan library yang Keras (Chollet and \&, 2020). Proses data augmentation terdiri dari horizontal flip, shear range, dan zoom range. Shear range dan zoom range memiliki nilai 0.2. Horizontal flip bekerja untuk memperbanyak data pelatihan dengan cara memutar gambar secara horizontal 90 derajat. Shear range menerapkan metode shear transformation (Goldman, 1991) untuk menambah variasi gambar dengan cara merotasi gambar dengan derajat tertentu, dan zoom range memperbesar gambar dengan skala tertentu dari gambar original.

\subsection{Konfigurasi Hyperparameter}

Pada tahap ini, beberapa parameter yang terkait dengan neural network dikonfigurasi. Konfigurasi hyperparameter $\mathrm{CNN}$ dilakukan untuk mendapatkan performa yang terbaik dari model klasifikasi.
Konfigurasi hyperparameter tidak dilakukan secara otomatis. Peneliti melakukan konfigurasi secara manual dari setiap parameter yang ada pada $\mathrm{CNN}$.

Parameter yang dikonfigurasi dalam penelitian ini adalah jenis arsitektur, database transfer learning, optimizer, loss function, dan jumlah epoch. Tabel 1 menunjukkan konfigurasi hyperparameter. MobileNetV2, VGG16, DenseNet201, dan Xception dipilih sebagai arsitektur CNN untuk mendeteksi citra masker wajah. Kinerja arsitektur tersebut untuk mendeteksi masker wajah akan dibandingkan.

MobileNetV2 masih menggunakan konvolusi yang mendalam dan terarah seperti MobileNetV1. MobileNetV2 menambahkan dua fitur baru: 1) linear bottlenecks, dan 2) shortcut connections between bottlenecks [13]. Di bagian bottleneck terdapat input dan output di antara model sementara lapisan dalam merangkum kemampuan model untuk mengubah input dari konsep tingkat yang lebih rendah (yaitu pixel) ke deskriptor tingkat yang lebih tinggi (yaitu kategori gambar). Pada akhirnya, seperti koneksi residual pada $\mathrm{CNN}$ tradisional, pintasan di antara bottleneks memungkinkan pelatihan yang lebih cepat dan akurasi yang lebih besar. Dalam penelitian ini, MobileNetV2 digunakan untuk mendeteksi citra masker wajah karena memiliki waktu komputasi yang cepat dengan performa yang baik.

VGG16 adalah CNN dengan 16 layer [14]. Model ini mendapatkan akurasi $92,7 \%$ pada pengujian top-5 di database ImageNet yang memiliki lebih dari 14 juta gambar yang termasuk dalam 1000 kelas. Model ini memiliki ukuran input default 224x224 dengan 3 saluran gambar RGB. Model memiliki filter $3 \times 3$ lapisan konvolusi dengan stride 1 dan lapisan maxpool $2 \times 2$ dengan stride 2 . Penelitian ini menggunakan VGG16 untuk mendeteksi citra masker wajah karena merupakan arsitektur yang umum digunakan dalam berbagai aplikasi. VGG16 juga biasa menggunakan arsitektur dengan pretrained model tetapi sangat lambat jika dilatih dari awal.

DenseNet201 menghubungkan setiap layer ke layer lainnya secara feed-forward [15]. Dalam penelitian ini, DenseNet201 digunakan untuk mendeteksi citra masker wajah karena memiliki beberapa kelebihan, yaitu mengurangi masalah vanishing gradient, memperkuat propagasi fitur, meningkatkan penggunaan kembali fitur, dan mengurangi jumlah parameter.

Xception adalah singkatan dari Extreme version of Inception [16]. Dalam penelitian ini, Xception digunakan untuk mendeteksi citra masker wajah karena lebih baik dari versi sebelumnya, Inception-v3 [17]. Xception memiliki jumlah parameter model yang sama dengan Inception-v3 tetapi mengungguli Inception-v3 pada dataset ImageNet dengan 17.000 kelas.

ImageNet adalah database gambar skala besar yang dibangun pada struktur WordNet [18]. ImageNet sangat berguna dalam pengenalan objek, 
mendeteksi citra, dan pengelompokan citra. Dalam hal transfer learning, database ImageNet digunakan sebagai dataset untuk melatih model CNN untuk membangun model. Dalam penelitian ini, pre-trained model diperoleh dari database ImageNet menggunakan library Keras.

Adam Optimizer adalah perpanjangan dari Stochastic Gradient Descent (SGD) yang memiliki adopsi lebih luas dalam pembelajaran mendalam untuk klasifikasi citra [19]. Adam optimizer efisien secara komputasi, kebutuhan memori rendah, dan mudah diimplementasikan. Penelitian ini menggunakan Adam optimizer untuk mengubah atribut neural network untuk meminimalkan loss.

Categorical Cross Entropy adalah loss function Cross Entropy untuk klasifikasi multiclass. Penelitian ini menggunakan Categorical Cross Entropy yang akan melatih output probabilitas $\mathrm{CNN}$ pada citra masker wajah. Fungsi aktivasi Softmax digunakan pada lapisan keluaran arsitektur CNN karena ini adalah satu-satunya fungsi aktivasi yang direkomendasikan untuk klasifikasi multi label.

Jumlah epoch yang digunakan dalam penelitian ini sebanyak 50 epoch. Alasan penentuan jumlah epoch adalah dengan pertimbangan waktu pelatihan dan spesifikasi komputer yang digunakan untuk melatih model. Berdasarkan hasil yang akan dibahas pada bab hasil, 50 epoch cukup untuk membuat akurasi data latih konvergen.

Tabel 1. Parameter CNN

\begin{tabular}{ll}
\hline Hyperparameter & Tipe \\
\hline Arsitketur & MobileNetV2, \\
& VGG16, \\
Database transfer & DenseNet201, \\
learning & Xception \\
& ImageNet \\
Optimizer & Adam \\
Loss Function & Categorical \\
& Cross Entropy \\
Jumlah epoch & 50 \\
\hline
\end{tabular}

\subsection{Training}

Pada tahap ini dilakukan proses pelatihan pada masing-masing arsitektur. Training dilakukan menggunakan proporsi dataset secara random dan diulang sebanyak 5 kali. Dari setiap kali proses training dilakukan uji coba menggunakan 5 cross validation. Proses training dan testing dilakukan pada komputer dengan spesifikasi CPU Intel ${ }^{\circledR}$ Core $^{\mathrm{TM}} \mathrm{i3}$ $3220 @ 3.30 \mathrm{GHz}$ dengan RAM 8 GB, kartu grafis AMD Radeon 5500 Series, storage yang digunakan adalah SSD 256 GB. Distribusi dataset akan dibagi menjadi $80 \%$ untuk pelatihan, $10 \%$ untuk validasi, dan $10 \%$ untuk pengujian. Rincian implementasi cross validation dibahas lebih detail pada tahap pengujian.

Pre-trained model untuk setiap arsitektur diperoleh dari database ImageNet di library Keras. Pre-trained model yang digunakan untuk proses pelatihan akan dimodifikasi dengan tidak memuat fully connected output layer. Hal ini dilakukan karena jumlah kelas pada citra masker wajah berbeda dengan kelas model pre-trained. Model pre-trained digunakan sebagai feature extractor yang outputnya akan dilakukan max pooling terlebih dahulu kemudian menjadi input ke Artificial Neural Network (ANN). ANN terdiri dari dua hidden layeri dan satu output layer. Setiap hidden layer memiliki 128 dan 64 neuron menggunakan activation function ReLu. Output layer terdiri dari 4 neuron menggunakan activation function Softmax. Persamaan (1) adalah activation function ReLu dan $\mathrm{z}$ adalah input untuk activation function. Persamaan (2) adalah perhitungan activation function Softmax yang memiliki input $x_{i}$, jumlah label kelas $n$, dan label kelas ke- $j$.

$R(z)=\max (0, z)$

$S\left(x_{i}\right)=\frac{e^{x_{i}}}{\sum_{j}^{n} e^{x_{j}}}$

\subsection{Testing}

Pada setiap epoch dilakukan proses validasi yang berasal dari 10\% jumlah dataset. Akurasi yang diperoleh dari data validasi tersebut tidak digunakan untuk melakukan update bobot pada lapisan neural network. Di sisi lain, akurasi model yang diperoleh dari data training digunakan untuk memperbarui bobot pada layer neural network

Pengujian dilakukan dengan menggunakan 10\% dari dataset citra masker wajah secara acak. Pengujian dilakukan dengan menggunakan 5 cross validation dan diulang sebanyak 5 kali. Dalam setiap algoritma, performa dari setiap cross validation akan diamati untuk melihat apakah performa yang dihasilkan dari masing-masing arsitektur stabil atau tidak.

\subsection{Perhitungan Performa}

Pada tahap ini dilakukan perhitungan performa dari arsitektur MobileNetV2, VGG16, DenseNet201, dan Xception. Performa yang dihitung adalah accuracy, precision, recall, F1 score, dan waktu komputasi. Perhitungan performa dilakukan pada setiap cross validation. Persamaan (3) menunjukkan rumus perhitungan accuracy.

Accuracy $=\frac{T P+T N}{T P+T N+F P+F N}$ precision

Persamaan (4) menunjukkan rumus perhitungan

Precision $=\frac{T P}{T P+F P}$

Persamaan (5) menunjukkan rumus perhiutngan recall. 
Recall $=\frac{T P}{T P+F N}$

Persamaan (6) menunjukkan rumus perhitungan F1 Score. Waktu komputasi dihitung ketika model melakukan 1 cross validation dengan menggunakan 50 epoch.

F1 Score $=\frac{\text { Precision } x \text { Recall }}{\text { Precision }+ \text { Recall }}$

\section{HASIL DAN PEMBAHASAN}

Pada tahap ini dibahas performa dari masingmasing arsitektur. Tabel 2 menunjukkan hasil performa masing-masing arsitektur. Xception memiliki rata-rata akurasi tertinggi sebesar 0,988 jika dibandingkan dengan arsitektur lainnya. Tujuan penggunaan akurasi rata-rata agar perhitungan kinerja dapat lebih digeneralisasikan karena eksperimen dilakukan dengan menggunakan 5 cross validation. Xception juga memiliki akurasi yang stabil dalam setiap cross validation. Gap akurasi tertinggi pada Xception adalah pada cross validation ke-2 dan ke-3 yaitu sebesar 0,011. DenseNet201 juga memiliki akurasi terbaik 0,987 pada cross validation ke-4. Namun, rata-rata akurasi Xception masih yang terbaik. Waktu komputasi Xception juga masih lebih baik jika dibandingkan dengan DenseNet201.

MobileNetV2 memiliki waktu komputasi ratarata tercepat yaitu 4081 detik. Waktu komputasi yang lebih cepat ini disebabkan oleh shortcut between bottlenecks memungkinkan proses training lebih cepat. Namun rata-rata akurasi MobileNetV2 masih di bawah Xception, yaitu 0,981 meskipun waktu pelatihan MobileNetV2 4,58 kali lebih cepat dari Xception. MobileNetV2 dapat dipilih sebagai salah satu arsitektur untuk mendeteksi masker wajah jika komputer yang digunakan untuk proses pelatihan memiliki spesifikasi yang rendah.

VGG16 memiliki waktu latihan rata-rata terlama yaitu 24705 detik. Selain itu, VGG16 memiliki akurasi rata-rata 0,582 yang kurang baik. Meskipun VGG16 adalah arsitektur yang umum digunakan untuk klasifikasi citra, VGG16 tidak cocok untuk mendeteksi citra masker wajah.

Akurasi digunakan untuk melihat performa dari tiap epoch yang saat proses training. Alasan hanya menggunakan akurasi adalah untuk melihat arsitektur yang digunakan overfitting atau tidak. Data yang digunakan dalam penelitian ini seimbang antara wajah bermasker dan tidak bermasker.

Gambar 3 menunjukkan grafik akurasi setiap epoch untuk MobileNetV2 dan DenseNet201 sedangkan Gambar 4 menunjukkan untuk VGG16 dan Xception dari cross validation ke-1 hingga ke-5. Garis biru menunjukkan akurasi untuk dataset training sedangkan garis putus-putus kuning untuk set dataset validasi.

Berdasarkan grafik akurasi dataset training dan validasi di tiap cross validation, MobileNetV2,
DenseNet201, dan Xception memiliki akurasi yang konvergen seiring bertambahnya epoch. Namun, akurasi VGG16 tidak cukup konvergen dan ini berdampak pada akurasi yang buruk di dataset pengujian. Xception memiliki gap akurasi yang tipis antara dataset training dan validasi di setiap epoch dan berdampak pada akurasi yang baik pada dataset testing.

\begin{tabular}{|c|c|c|c|c|c|c|c|}
\hline Arsitektur & Metric & CV1 & CV2 & CV3 & CV4 & CV5 & Rata-rata \\
\hline \multirow{5}{*}{ 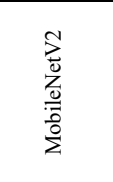 } & ACC & 0.980 & 0.978 & 0.992 & 0.978 & 0.978 & 0.981 \\
\hline & PREC & 0.980 & 0.978 & 0.992 & 0.978 & 0.978 & 0.981 \\
\hline & REC & 0.980 & 0.978 & 0.992 & 0.978 & 0.978 & 0.981 \\
\hline & F1SCORE & 0.980 & 0.978 & 0.992 & 0.978 & 0.978 & 0.981 \\
\hline & TIME (S) & 3686 & 3638 & 3945 & 4485 & 4652 & 4081 \\
\hline \multirow{5}{*}{ 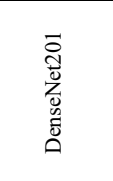 } & $\mathrm{ACC}$ & 0.982 & 0.984 & 0.986 & 0.990 & 0.990 & 0.987 \\
\hline & PREC & 0.982 & 0.984 & 0.986 & 0.990 & 0.990 & 0.987 \\
\hline & REC & 0.982 & 0.984 & 0.986 & 0.990 & 0.990 & 0.987 \\
\hline & F1SCORE & 0.982 & 0.984 & 0.986 & 0.990 & 0.990 & 0.987 \\
\hline & TIME (S) & 16561 & 18638 & 20933 & 21711 & 20782 & 19725 \\
\hline \multirow{4}{*}{$\begin{array}{l}0 \\
0 \\
0 \\
>\end{array}$} & PREC & 0.488 & 0.472 & 0.477 & 0.529 & 0.944 & 0.582 \\
\hline & REC & 0.488 & 0.472 & 0.477 & 0.529 & 0.944 & 0.582 \\
\hline & F1SCORE & 0.488 & 0.472 & 0.477 & 0.529 & 0.944 & 0.582 \\
\hline & TIME (S) & 24253 & 24483 & 24689 & 25032 & 25070 & 24705 \\
\hline \multirow{5}{*}{ 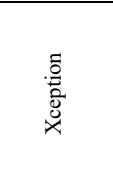 } & ACC & 0.990 & 0.993 & 0.988 & 0.982 & 0.986 & 0.988 \\
\hline & PREC & 0.990 & 0.993 & 0.988 & 0.982 & 0.986 & 0.988 \\
\hline & REC & 0.990 & 0.993 & 0.988 & 0.982 & 0.986 & 0.988 \\
\hline & F1SCORE & 0.980 & 0.978 & 0.992 & 0.978 & 0.978 & 0.981 \\
\hline & TIME (S) & 17164 & 17969 & 18574 & 18875 & 18788 & 18274 \\
\hline
\end{tabular}

Xception memiliki akurasi terbaik jika dibandingkan dengan arsitektur lain untuk mendeteksi citra masker wajah. Xception direkomendasikan untuk mendeteksi citra masker wajah. Namun, Xception membutuhkan waktu yang komputasi yang lama, tetapi masih lebih baik jika dibandingkan dengan VGG16 dan DenseNet201.

MobileNetV2 memiliki waktu komputasi tercepat yaitu 4081 detik dan memiliki akurasi 0.981 atau hanya selisih 0.007 jika dibandingkan dengan arsitektur Xception. MobileNetV2 memiliki time to performance yang sangat baik dikarenakan waktu komputasi yang dimiliki 4.03 kali lebih cepat dibandingkan Xception dengan selisih akurasi 0.007.

\section{KESIMPULAN}

Pendeteksian citra masker wajah dapat diselesaikan menggunakan CNN dengan transfer learning. Berdasarkan percobaan menggunakan 5cross validation dan 50 epoch, Xception yang dikombinasikan dengan transfer learning dari database ImageNet dapat mengklasifikasikan citra masker wajah dengan akurasi rata-rata dan waktu komputasi 0.988 dan 18274 detik. MobileNetV2 yang dikombinasikan dengan transfer learning dapat mengklasifikasikan citra masker wajah dengan akurasi dan waktu komputasi masing-masing 0.981 dan 4081 detik. 

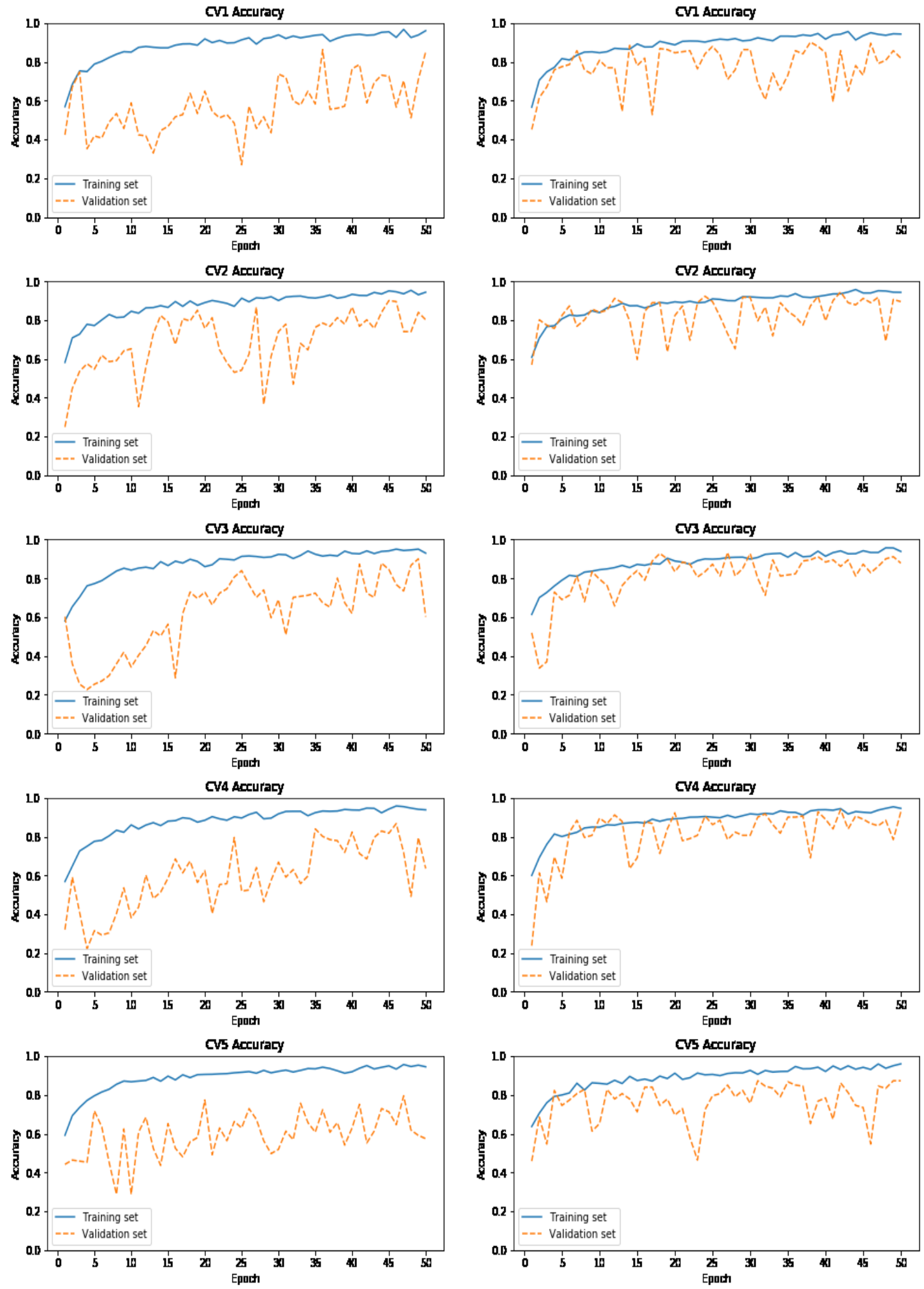

(a)

(b)

Gambar 3. Grafik akurasi dari tiap epoch untuk MobileNetV2 (a) dan DenseNet201 (b) mulai cross validation ke-1 hingga ke-5 

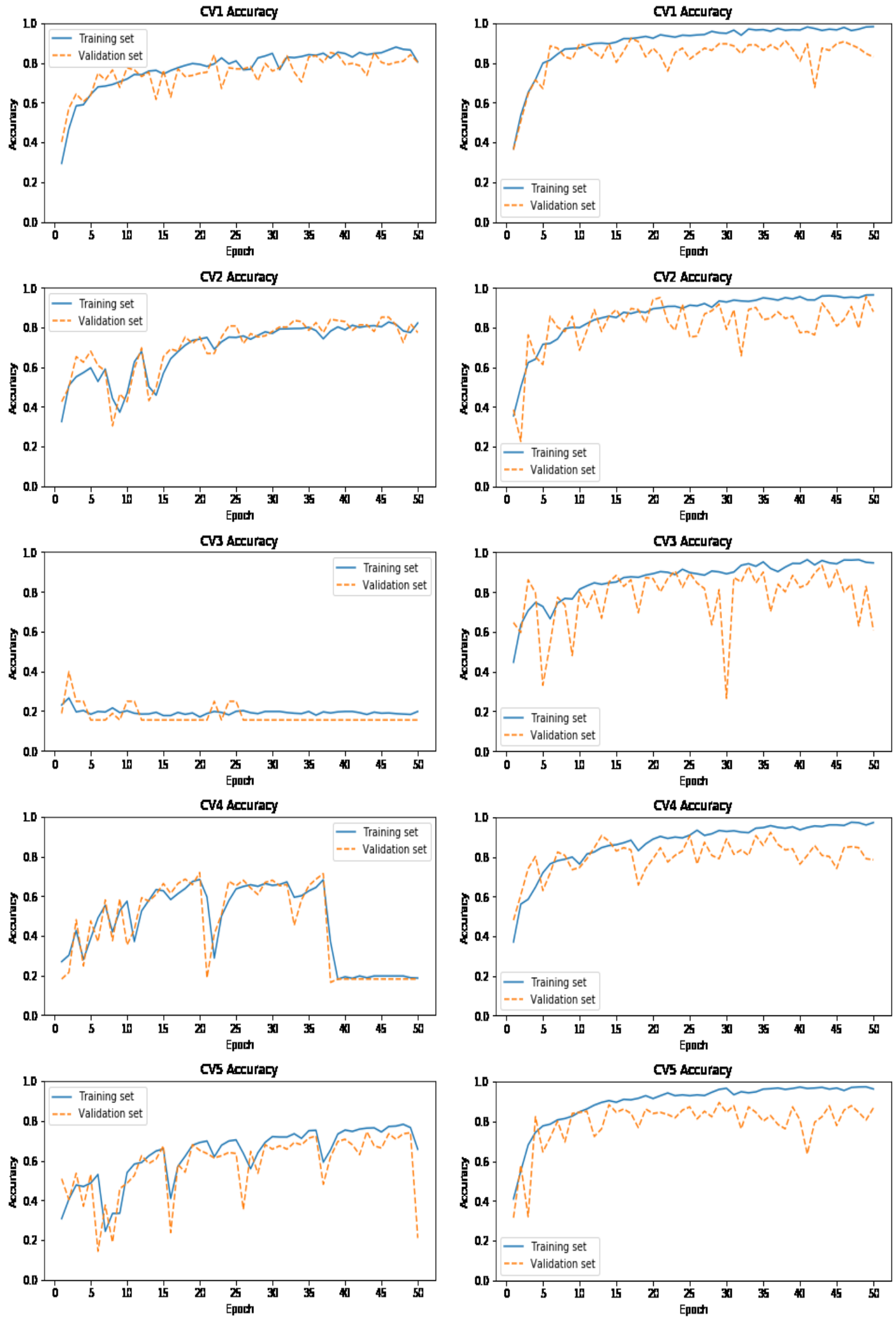

(a)

(b)

Gambar 4. Grafik akurasi dari tiap epoch untuk VGG16 (a) dan Xception (b) mulai cross validation ke-1 hingga ke-5 
Di dunia industri, model CNN dengan transfer learning diharapkan dapat diterapkan secara langsung untuk mendeteksi orang tidak bermasker yang berguna untuk memperketat protokol kesehatan. Xception dapat dipilih sebagai arsitektur yang memiliki akurasi terbaik namun membutuhkan waktu komputasi yang lebih lama. Jika komputer dengan spesifikasi tinggi tersedia, maka Xception adalah pilihan yang tepat. Namun jika komputer memiliki spesifikasi yang rendah, maka MobileNetV2 dapat dipilih karena memiliki waktu komputasi yang lebih cepat. Untuk penelitian selanjutnya, ada peluang untuk menerapkan pendeteksian masker wajah dengan menambahkan tahapan preprocessing citra, sehingga jika terdapat noise pada citra, maka noise dapat diminimalisir dengan baik.

\section{DAFTAR PUSTAKA}

AL-SAFFAR, A.A.M., TAO, H. AND TALAB, M.A., 2017. Review of deep convolution neural network in image classification. Proceeding - 2017 International Conference on Radar, Antenna, Microwave, Electronics, and Telecommunications, ICRAMET 2017, 2018-Janua, pp.26-31.

BUDIMAN, B., 2021. Pendeteksian Penggunaan Masker Wajah Dengan Metode Convolutional Neural Network. Jurnal Ilmu Komputer dan Sistem Informasi, Vol.9 No.1.

CHOLLET, F. AND \& O., 2020. Keras: the Python deep learning API. [online] Keras: the Python deep learning API. Available at: $<$ https://keras.io/> [Accessed 18 Dec. 2020].

ET AL., R.K., 2021. A Comparative Analysis of Variant Deep Learning Models for COVID-19 Protective Face Mask Detection. Turkish Journal of Computer and Mathematics Education (TURCOMAT), 12(6), pp.28412848.

GE, S., LI, J., YE, Q. and LUO, Z., 2017. Detecting masked faces in the wild with LLE-CNNs. Proceedings - 30th IEEE Conference on Computer Vision and Pattern Recognition, CVPR 2017, 2017-Janua, pp.426-434.

GOLDMAN, R.N., 1991. More matrices and transformations: Shear and pseudoperspective. In: Graphics Gems II. Elsevier Inc.pp.338-341.

GRASSI, M. AND FAUNDEZ-ZANUY, M., 2007. Face recognition with facial mask application and neural networks. Lecture Notes in Computer Science (including subseries Lecture Notes in Artificial Intelligence and Lecture Notes in Bioinformatics), 4507 LNCS, pp.709-716.

HAN, W., HUANG, Z., KUERBAN, A., YAN, M. AND FU, H., 2020. A Mask Detection Method for Shoppers under the Threat of COVID-19
Coronavirus. In: Proceedings - 2020 International Conference on Computer Vision, Image and Deep Learning, CVIDL 2020. Institute of Electrical and Electronics Engineers Inc.pp.442-447.

JAGADEESWARI, C. AND THEJA, M.U., 2020. Performance Evaluation of Intelligent Face Mask Detection System with various Deep Learning Classifiers Keywords : International Journal of Advanced Science and Technology, 29(11), pp.3074-3082.

JIGNESH CHOWDARY, G., PUNN, N.S., SONBHADRA, S.K. AND AGARWAL, S., 2020. Face Mask Detection Using Transfer Learning of InceptionV3. Lecture Notes in Computer Science (including subseries Lecture Notes in Artificial Intelligence and Lecture Notes in Bioinformatics), 12581 LNCS, pp.81-90.

LARXEL, 2020. Face Mask Detection | Kaggle. [online] Available at: $<$ https://www.kaggle.com/omkargurav/facemask-dataset $>$ [Accessed 1 Feb. 2021].

NAGRATH, P., JAIN, R., MADAN, A., ARORA, R., KATARIA, P. AND HEMANTH, J., 2021. SSDMNV2: A real time DNN-based face mask detection system using single shot multibox detector and MobileNetV2. Sustainable Cities and Society, 66(December 2020).

O'SHEA, K. AND NASH, R., 2015. An Introduction to Convolutional Neural Networks. [online] (November). Available at: $<$ http://arxiv.org/abs/1511.08458>.

PAK, M. AND KIM, S., 2018. A review of deep learning in image recognition. Proceedings of the 2017 4th International Conference on Computer Applications and Information Processing Technology, CAIPT 2017, 2018Janua, pp.1-3.

SIEGFRIED, I.M., 2020. Comparative Study of Deep Learning Methods in Detection Face Mask Utilization. PrePrint, pp.1-7.

TAN, C., SUN, F., KONG, T., ZHANG, W., YANG, C. AND LIU, C., 2018. A Survey on Deep Transfer Learning. Lecture Notes in Computer Science (including subseries Lecture Notes in Artificial Intelligence and Lecture Notes in Bioinformatics), [online] 11141 LNCS, pp.270-279. Available at: $<$ http://arxiv.org/abs/1808.01974> [Accessed 31 May 2021].

VINITHA, V. AND VELANTINA, V., 2020. Covid19 Facemask Detection With Deep Learning and Computer Vision. International Research Journal of Engineering and Technology (IRJET), 7(8), pp.3127-3132. 